$1-15-2016$

\title{
Advancing Concrete Strength Prediction using Non-destructive Testing: Development and Verification of a Generalizable Model
}

Kamran Amini

Cleveland State University

Mehdi Jalalpour

Cleveland State University, m.jalapour@csuohio.edu

Norbert Delatte

Cleveland State University

Follow this and additional works at: https://engagedscholarship.csuohio.edu/encee_facpub

Part of the Construction Engineering and Management Commons

How does access to this work benefit you? Let us know!

\section{Original Citation}

Amini, K., Jalalpour, M., and Delatte, N. (2016). "Advancing concrete strength prediction using nondestructive testing: Development and verification of a generalizable model." Constr.Build.Mater., 102, Part $1762-768$.

This Article is brought to you for free and open access by the Civil and Environmental Engineering at EngagedScholarship@CSU. It has been accepted for inclusion in Civil and Environmental Engineering Faculty Publications by an authorized administrator of EngagedScholarship@CSU. For more information, please contact library.es@csuohio.edu. 


\title{
Advancing concrete strength prediction using non-destructive testing: Development and verification of a generalizable model
}

\author{
Kamran Amini, Mehdi Jalalpour, Norbert Delatte
}

\section{Introduction}

Estimating the in-situ compressive strength is imperative for evaluating the quality of existing concrete structures during their service lives. In many cases, however, the actual condition of the materials used in construction is highly variable, and no information exists regarding the specifications of the concrete. This information includes age, concrete ingredients, construction quality, curing method, and concrete mechanical properties. Nondestructive tests (NDTs) can be used in such situations to estimate the in-situ physical properties of concrete to circumvent the need for in-situ sampling and compressive testing of concrete cores [1]. Due to the increase in the need for assessment of damaged concrete structures, NDT has gained popularity in recent years, and many NDT methods are available such as cast in-place cylinder test, ultrasonic pulse velocity (UPV), rebound hammer (RH), and resonant frequency test [2]. The procedures for performing these NDTs are outlined in ACI 228.1R-13 [3]. This paper focuses on RH and UPV.

Rebound hammer testing is a simple NDT method that provides an approximate indication of concrete quality and is deemed as a supplementary and in-place technique for estimating compressive strength of cast-in-place concrete [4]. Test results are measured as rebound number (RN). Many researchers attempted to establish a relationship between $\mathrm{RN}$ and compressive strength [5-8]. Szilágyi et al. [5] added to the fundamental understanding of the rebound surface hardness of concrete by introducing a phenomenological constitutive model that can be formulated for the surface hardness of concrete as a time dependent material property. Their results indicated that $\mathrm{RN}$ is significantly affected by the near surface properties of the hardened concrete such as smoothness, carbonation, size and type of the aggregates, and age of the concrete. Similar 
results are reported by $\mathrm{ACI}$ committee 228 [6]. Hence, $\mathrm{RH}$ is considered as a non-electronic, supplementary, in-place technique to predict the compressive strength of hardened concrete $[4,8]$. Qasrawi [7] also reported the unsuitability of the individual use of rebound hammer to estimate concrete strength.

Ultrasonic pulse velocity (UPV) method measures elastic properties of concrete and has been used to estimate the quality of in-situ concrete including the dynamic modulus of elasticity and therefore, compressive strength [9-11]. Yildirim et al. [12] investigated the effects of water to cement ratio, maximum aggregate size, aggregate type, and fly ash addition on the dynamic modulus of elasticity of low quality concrete using UPV. Based on their results, a strong relationship was achieved between the modulus of elasticity and ultrasound pulse velocity. However, the UPV test has been generally used to detect discontinuities in hardened concrete and is more sensitive to internal properties including density of concrete [4]. The empirical issues of using this method such as materials constitutions and calibration are explained in $[13,14]$.

A combination of NDTs therefore, may be advantageous for predicting concrete strength, because the results obtained from a single test, as discussed above, might be inconclusive [15]. However, early investigations on this combined usage yielded mixed results. For instance, Breysse [16] concluded that the effectiveness of combining the evaluation of two or more NDTs has been controversial. Moreover, Carvalho et al. [17] applied statistical techniques to evaluate the reliability of UPV and RH to evaluate the compressive strength of the concrete in bridges. Their results revealed lack of consistency in the correlation of UPV and RH on four tested bridges. ACl 228.1R-03 [6] also reported that a combination of NDTs only provides marginal improvements over a single method. Nevertheless, recently, there is a growing literature on documenting the advantages of application of multiple NDTs to increase reliability and accuracy of predictions [7,18-21]. Ravindrajah et al. [22] reported promising results on compressive strength estimation of recycled-aggregate concrete using combined UPV and $\mathrm{RH}$. Kheder [23] investigated concrete strength prediction using UPV and RH in conjunction with concrete mix proportions and density. They compared their results with cores taken from actual structures, and observed good predictive accuracy. The advantage of using a combination of RH and UPV, for example, can be described by the fact that the results of each test is influenced by different properties of the hardened concrete [7,21,24,25]. A number of regression models using a combination of UPV and RH to predict compressive strength have been developed recently [26-29]. The seminal work by Huang et al. [19] developed a multivariate regression model to predict compressive strength using the combined $\mathrm{UPV} / \mathrm{RH}$ for a comprehensive data on the mixture proportions, curing conditions, and age of the concrete. They showed that their proposed model yields more accurate predictions in comparison with other regression models.

The real conditions of the structures may be highly variable spatially due to the variability of materials received, their properties and sporadic supervision [1,7]. Therefore, realistically, information about concrete mixture proportions and construction might not be available for in-situ predictions. However, a look at the above body of work reveals most of the developed models use this information. In the present article, accurate predictive models for compressive strength of concrete specimens are derived using only NDT results. Through rigorous statistical tests with threefold cross-validation, both UPV and RN were determined statistically significant variables for predictive modeling. Therefore, a multivariate regression model based on a combination of these NDT results was proposed and verified for accuracy through prediction of independent data. Finally, concrete quality classification using RN and UPV is proposed based on unsupervised machine learning $\mathrm{k}$-means clustering method.

\section{Experimental procedures and independent data collection}

A total of 84 concrete cylinders with unknown information about their age, mixing ratios, and without any prior knowledge of their expected compressive strength were first tested in a laboratory using the following NDTs.

The rebound hammer ( $\mathrm{RH}$ ) test was conducted in accordance with ASTM C805 [31]. The test began by a careful selection and preparation of the sample surface for testing. Once the plunger of the RH is pressed to the concrete surface, a spring-pulled mass rebounds back with a rebound distance. The extent of the rebound is a measure of the surface hardness. This measured value is designated as the rebound number (RN), which is on a graduated scale. At least 10 readings for each sample were performed and their average was used to determine the RN for each sample. A concrete with high strength and high stiffness absorbs less energy, leading to a higher rebound value and a higher RN [6].

The ultrasonic pulse velocity (UPV) test was conducted according to ASTM C597 [30]. The UPV test can be conducted by three different methods; direct, semi-direct, and indirect method, out of which the direct method is the most accurate method [3] and was used in this work. However, in the field, using a direct method is impractical, and the indirect method is used instead. This test determines the required time for a vibration pulse of an ultrasonic frequency to travel through a concrete specimen with known dimensions. The pulse velocity is, therefore, determined and reported. Based on the obtained velocity, the uniformity, quality, and strength of tested specimens can be estimated. The changes in the wave speed indicate the variability of the dynamic modulus of elasticity and the density of the material [3]. RH and UPV tests were repeated three times on each specimen and the average values were reported. All the cylinders were secured from movement and all the tests were conducted on the center of the surface of the cylinders.

After all the NDTs were conducted, the compressive strengths of all the specimens were destructively determined according to ASTM C39 [32]. For this test, the cylinders were placed in a compression machine and were loaded until failure and the maximum compressive strength was recorded for each concrete cylinder. The combination of UPV, $\mathrm{RH}$, and compressive test results forms the "in-house" data for this study.

An additional 88 data points were also collected from six different research papers $[26,33-37]$. These data are termed the "independent" data, and will be used for testing the proposed models.

\section{Data modeling and classification approach}

For all of the analyses in this paper, the UPV reading was scaled by dividing by $10^{3}$. We begin with single variable linear regression analysis to establish the relation between compressive strength with RN and UPV separately. A regression model is expressed as follows:

$\boldsymbol{y}=\mathbf{X} \boldsymbol{\beta}+\boldsymbol{\epsilon}$

where $\boldsymbol{y}$ is the vector of responses, $\mathbf{X}$ is the matrix that collects all the exogenous variables, which are hypothesized to predict or influence the response, $\boldsymbol{\beta}$ is the vector of model parameters that will be estimated based on the available data, and $\varepsilon$ is the vector of noise or random fluctuations. In this study, the response data are concrete compressive strengths, and exogenous variables include RN, UPV and possibly their exponents with an intercept (constant) term. Important assumptions in regression models are as follows. It is assumed that responses are independent, and the random noise vector is zero-mean, uncorrelated and follows normal distribution. This last assumption also means that the residuals from any fitted 
model (difference between predictions and actual observations) should not show an identifiable structure $[38,39]$. Therefore, before making inferences using regression models, one should perform residual analysis. If these assumptions are met, then the model predicts the expected value or average of the response given the observed exogenous data. The most widely used models for compressive strength are: (1) second order polynomial, (2) power, and (3) exponential $[16,26,40,41]$. These models, for the case of $R N$, are expressed respectively as follows.

$E\left[f_{c}^{\prime} \mid \mathrm{RN}\right]=\beta_{0}+\beta_{1} R N+\beta_{2} R N^{2}$

$E\left[f_{c}^{\prime} \mid \mathrm{RN}\right]=\beta_{0} R N^{\beta_{1}}$

$E\left[f_{c}^{\prime} \mid \mathrm{RN}\right]=\beta_{0} e^{\beta_{1} R N}$

In the above equations, $f_{c}^{\prime}$ is the compressive strength, $E[$.$] is the$ expected value operator, $R N$ is the reported rebound number, and the coefficients $(\beta)$ are estimated from the data using, for example, maximum likelihood method. Equations for the case of UPV are similar. These models were fitted to the data obtained in this study, and then residuals were evaluated and analyzed.

Multivariate regression models were also developed. Prior to this analysis, a power transformation analysis was also conducted and it was determined that there is no need to transform the compressive strength values. With the goal of deriving models generalizable to prediction of new data, a threefold cross-validation data partitioning scheme was pursued. First, the in-house data was randomly partitioned into three groups (each with 28 data points), and then two of these groups were used as "training sets" for fitting a regression model. The remainder of the dataset ("test set" or "cross-validation set") was then predicted using this developed model. This procedure was repeated three times, until each group was used exactly once in the test set. This phase of research was also used to assess the predictive contribution of the following exogenous variables $R N, U P V, R N^{2}, U P V^{2}, R N \times U P V$ using forward substitution and backward elimination [42]. This procedure began with choosing a statistical significance level of $\alpha=0.05$. For this discussion, a full model is defined as the model with at least one more exogenous variable in comparison to the nested model, which is the same model with one variable removed. A full model is fitted first. The residual sum of squares for this model is then computed using the following equation:

$\operatorname{Rss}_{1}=\sum_{i=0}^{n}\left(\hat{y}_{i}-y_{i}\right)^{2}$

where $y_{1}$ is the model prediction, $y_{i}$ is the actual data point, and $n=28$ is the number of test data. Next, a variable is removed creating a nested model with $p_{2}$ variables and the Rss $_{2}$ is evaluated for this model. The null hypothesis is that the full model does not provide a significantly better prediction. Therefore, the test statistics under this null hypothesis follows $F$ distribution with $n-p_{2}$ degrees-of-freedom and is expressed as [38]:

$F=\frac{\mathrm{Rss}_{1}-\mathrm{Rss}_{2}}{\frac{\mathrm{Rss}_{2}}{n-p_{2}}}$

If the above test statistic was greater than the critical value for $F$ distribution--at the chosen significance level--the variable under study is retained in the model. Otherwise, the variable is removed. This procedure was performed for all the variables individually. For the forward substitution phase, the analysis began with a null model consisting only of the average of responses (intercept term, which is a vector of ones) and new variables are then added to the model sequentially. If prediction improvement was statistically significant, the new variable was added to the model. This process continued until all the variables were assessed.

One can imagine that including higher order polynomial terms in proposed models may improve prediction accuracy. For example, a third-order model including linear, quadratic and cubic terms for RN may outperform a quadratic model. Therefore, using the partitioned in-house data, the optimal model order was established with the following procedure as well. The training error is determined as:

$J_{\mathrm{tr}}=\frac{\sum_{i=0}^{n_{\mathrm{tr}}}\left(\hat{y}_{i}-y_{i}\right)^{2}}{n_{\mathrm{tr}}}$

where $n_{\mathrm{tr}}$ is the number of samples in the training set (i.e. 54 samples). The cross-validation error is also defined similarly. These errors were then evaluated and averages as a function of model order were plotted. Models up to order four were investigated (four sets of errors). It is noted, as expected, that the average training error decreases with increasing the model order. However, the average cross-validation error appears as a polynomial function with a local minimum which indicates the optimal model order. This is because the purpose of this phase was to avoid "overfitting" models to the in-house data. This bias-variance tradeoff is common in statistical predictive modeling [39].

Finally, to classify the comprehensive data obtained in this study, a variant of $\mathrm{k}$-means clustering method was applied using combined NDT results. Number of clusters were chosen iteratively through an optimization procedure outlined in [43]. The algorithm (kMeans++) iteratively minimizes the sum of distances from each observation to its cluster centroid over all clusters to partition the data into mutually exclusive clusters [44].

\section{Results and discussion}

\subsection{Univariate models using individual NDT results}

Regression lines using univariate models to predict the in-house compressive strength data with UPV and RN are shown in Fig. 1. It appears that power and exponential models overestimate compressive strength when RN and UPV values are greater than 35 and $3800 \mathrm{~m} / \mathrm{s}$, respectively. The situation is more pronounced for the case of RN. On the other hand, the second-order polynomial model may predict negative values for compressive strength when the RN is less than 10 and/or UPV is less than $3000 \mathrm{~m} / \mathrm{s}$. These negative predictions of compressive strength can be attributed to the scarcity of the available data in this range or to the fact that lower strengths of concrete increases the prediction intervals of the true compressive strength [7].

Fig. 2 illustrates the residuals of these models versus the predicted compressive strength of the cylindrical specimens. It can be seen that the residual plots of exponential and power models show systematic trends indicating that these models are not adequate to predict the compressive strength of the concrete specimens. Moreover, it can be seen that for both UPV and RN the residual requirements are only met by second order polynomial model. Therefore, it appears that only polynomial models may be adequate for statistical inference and predictions. These two models were next used for independent data prediction.

\subsection{Independent data prediction using univariate polynomial models}

Following the goal of this study (prediction of independent data), polynomial models from the previous section were used to predict the independent data collected from different research papers $[26,33-37]$. The predictions along with residual plots are shown in Fig. 3. While the model with UPV seems to predict the 

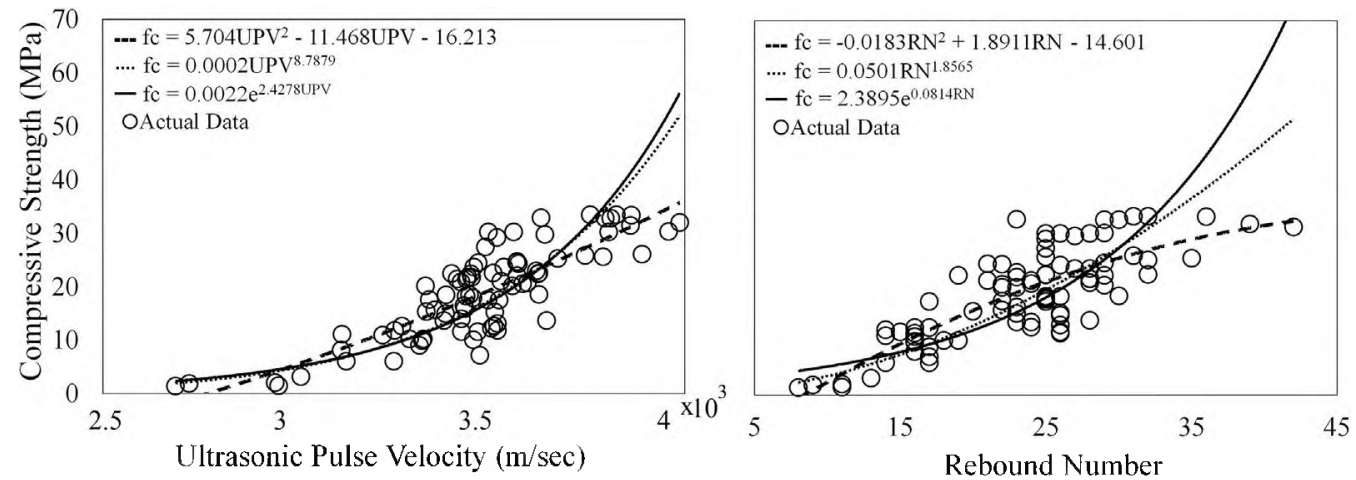

Fig. 1. Accuracy assessment of the developed univariate models based on: exponential, power, and second order polynomial laws.

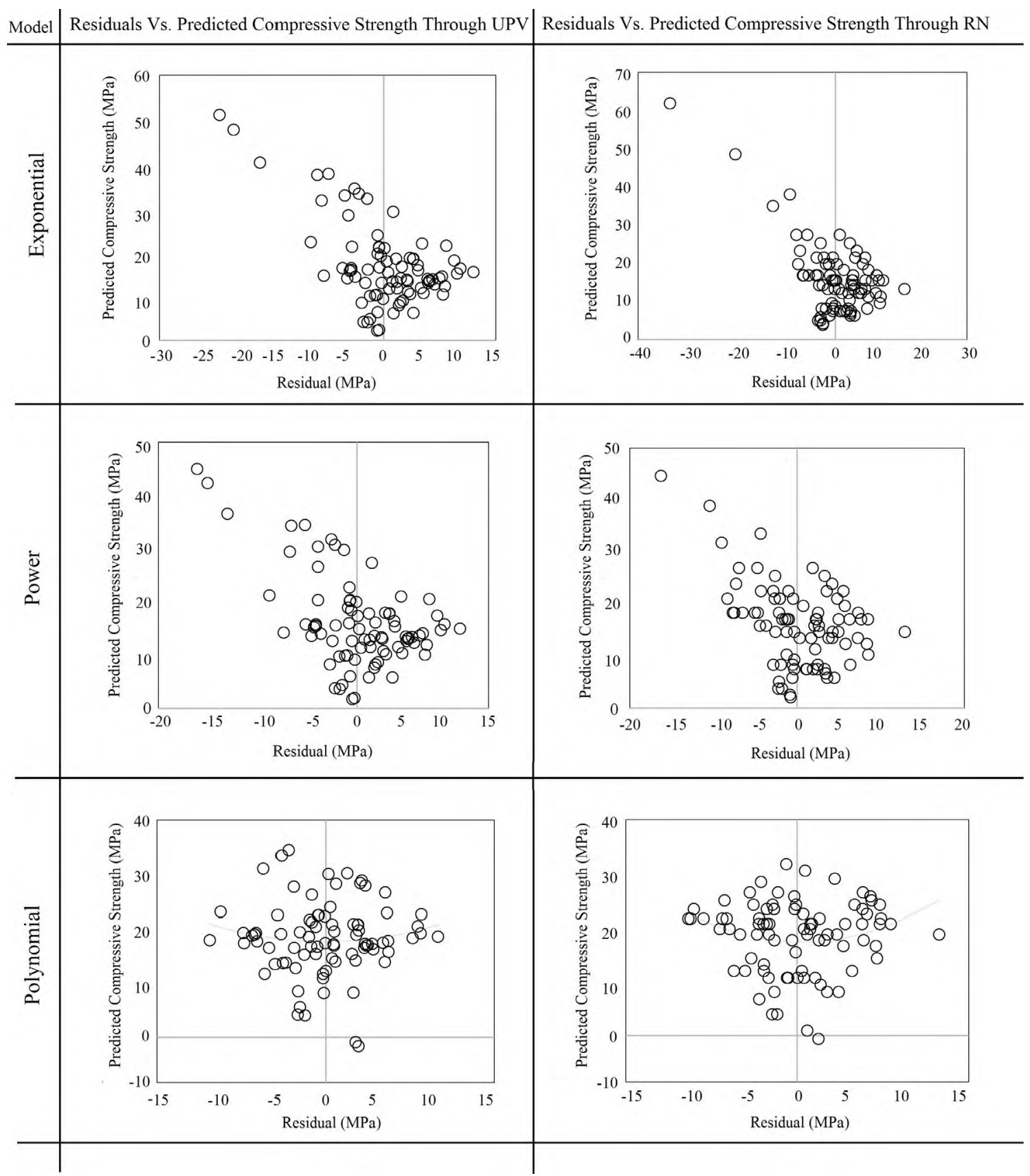

Fig. 2. Predicted compressive strength versus residuals for different models based on UPV and RN results of the in-house data. 


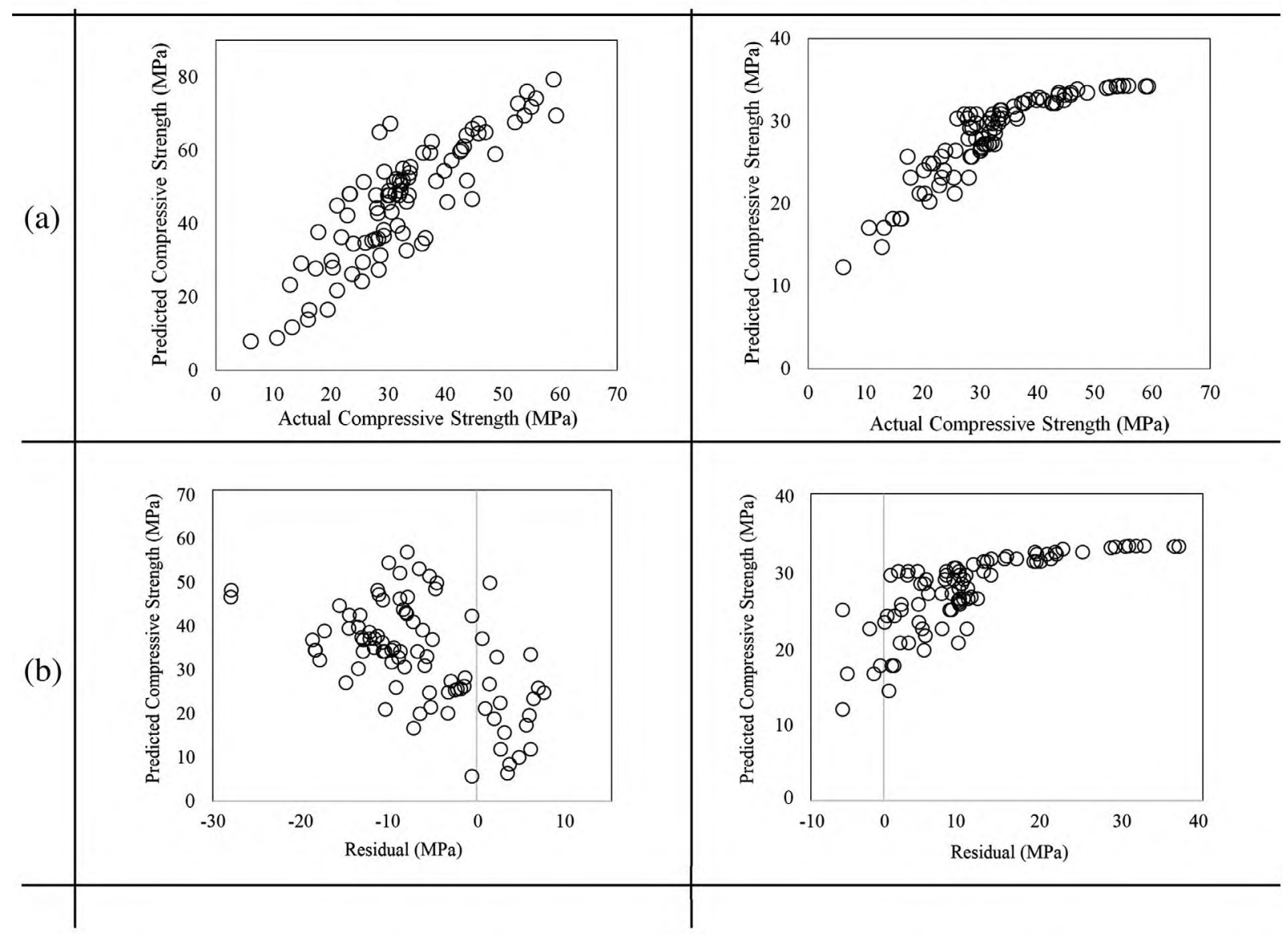

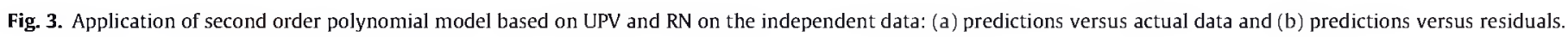

data with acceptable accuracy, the residuals appear to have a structure, which implies that the model may have a systematic bias when applied on independent data. Moreover, it can be seen on the right panel of Fig. 3(a) that the model based on RN significantly underestimates the actual independent data, specifically at higher values. For instance, an actual compressive strength of $50 \mathrm{MPa}$ is predicted at $32 \mathrm{MPa}$.

Therefore, using a single NDT result seems inadequate to predict the independent data. This result is in agreement with results of other research in this field, where it is argued that the individual NDT may not yield reliable models $[7,21,45]$.

\subsection{Predictive models using combined NDT results}

For these analyses, the in-house data was partitioned into three sets, and then optimal order selection began. The model order was systematically increased from linear to cubic term for both UPV and RN variables, and training and cross-validation errors were determined. The results indicated that the optimal model order was quadratic polynomial as the average test error was minimized at this model order.

Next, testing statistical significance for these variables was performed. For brevity, results for forward selection are only presented here. The null model was chosen to be the intercept only, and each variable contribution was assessed in isolation. The results show that both RN and UPV produce a significantly better prediction as can be seen with the $p$-value matrix shown in Table 1. The interaction variable ( $U P V * R N$ ) was not significant in any of the partitions. Therefore, based on the data obtained in this study, predicting the strength of concrete may be more accurate with results
Table 1

p-Value matrix.

\begin{tabular}{lccc}
\hline Variable & \multicolumn{3}{c}{ Partition } \\
\cline { 2 - 4 } & 1 & 2 & 3 \\
\hline RN & 0.000 & 0.003 & 0.000 \\
UPV & 0.000 & 0.030 & 0.000 \\
RN $^{2}$ & 0.000 & 0.001 & 0.000 \\
UPV $^{2}$ & 0.000 & 0.019 & 0.000 \\
\hline
\end{tabular}

from a combination of RN and UPV. Moreover, backward elimination on this full model indicated that no variable could be removed. All these analyses were repeated with a fivefold cross-validation with no changes on the inferences.

Finally, each model (obtained by fitting to $2 / 3$ of the data) was used to predict its corresponding test set of the data. The predictions are presented in Fig. 4, where the accuracy of models can be verified. The best model from these analyses is chosen as the average of the three, and is expressed as:

$$
\begin{aligned}
E\left[f_{c}^{\prime} \mid R N, U P V\right]= & 10^{3}(0.10983+0.00157 R N-0.79315 \mathrm{UPV} \\
& \left.-0.00002 R N^{2}+1.29261 U P V^{2}\right)
\end{aligned}
$$

\subsection{Independent data prediction using the proposed multivariate model}

As mentioned before, the true power of NDTs may lie in their capabilities for independent data predictions. Therefore, the proposed model is used for prediction of the independent data 


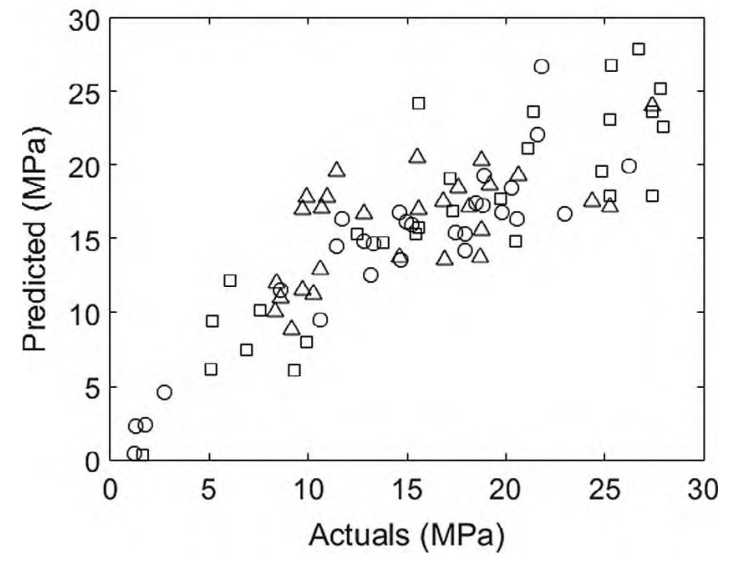

Fig. 4. Cross-validation prediction results for multivariate models using combined NDTs for the in-house compressive strength data.

acquired in this study. Fig. 5 shows the predicted values against the actual compressive strength data. The two diagonal dashed lines show the upper and lower 95\% prediction interval depicting the range one expects actual responses to fall in. It can be observed that the majority of the points lie close to the predicted mean, the solid diagonal line, which verifies accuracy of the proposed model. The average of the ratio between measured and predicted values for compressive strength is 0.955 . There are, however, a few outliers. As another method to verify model predictions, we can define model error as the absolute value of difference between actual data and predictions. Using this criterion, about $65 \%$ of the independent data are predicted with less than $10 \%$ error, $75 \%$ with less than $15 \%$ error, and $82 \%$ with an error of less than $20 \%$. Overall, the proposed model appears to predict independent data with acceptable accuracy, and may be useful for prediction of a wide range of new data. Fig. 6 demonstrates the residual plot of the developed model using combined UPV and RN. It can be observed that residuals appear to be zero-mean without a structure. Therefore, the proposed model seems adequate for predictions and inferences.

\subsection{Concrete quality classification based on clustering}

Leslie and Cheesman [46] reported that the qualitative condition of the concrete can be classified as a function of UPV. Their results indicated that the variation of UPV as a function of concrete soundness might be used to classify the quality of concrete as either very good, good, fair, poor, and very poor. Because the

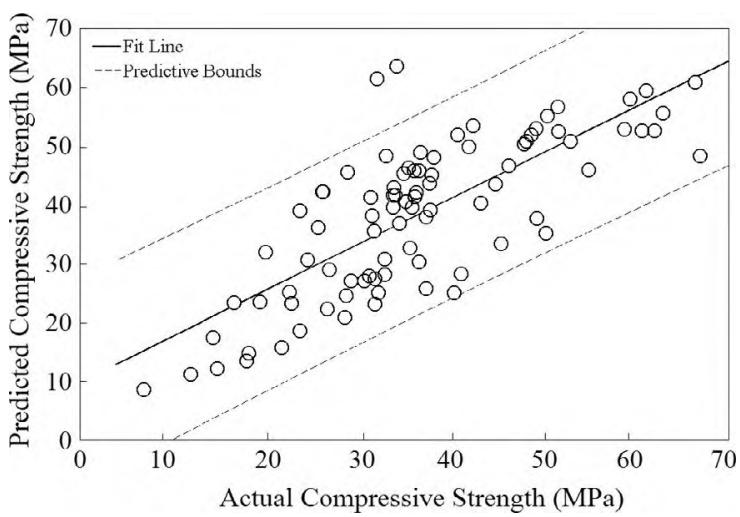

Fig. 5. Prediction of the independent data using the model proposed in Eq. (8).

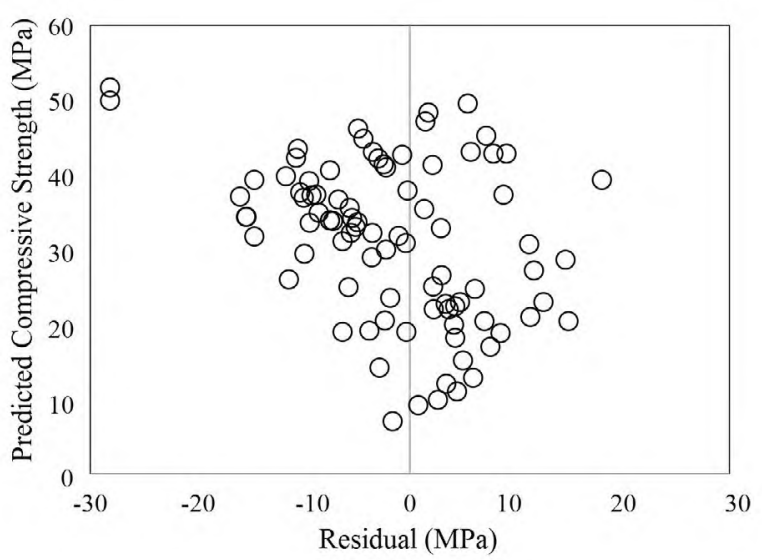

Fig. 6. Residuals plot of the model proposed in Eq. (8) applied to the independent data.

Table 2

Cluster centroids in space in all directions.

\begin{tabular}{ccccc}
\hline $\begin{array}{c}\text { Cluster } \\
\text { number }\end{array}$ & $\begin{array}{c}\text { UPV } \\
(\mathrm{m} / \mathrm{s})\end{array}$ & RN & $\begin{array}{c}\text { Compressive strength } \\
(\mathrm{MPa})\end{array}$ & $\begin{array}{c}\text { Concrete } \\
\text { quality }\end{array}$ \\
\hline l & 5000 & 46 & 40 & Very good \\
II & 4500 & 35 & 30 & Good \\
III & 4000 & 27 & 20 & Fair \\
IV & 3500 & 19 & 10 & Poor \\
\hline
\end{tabular}

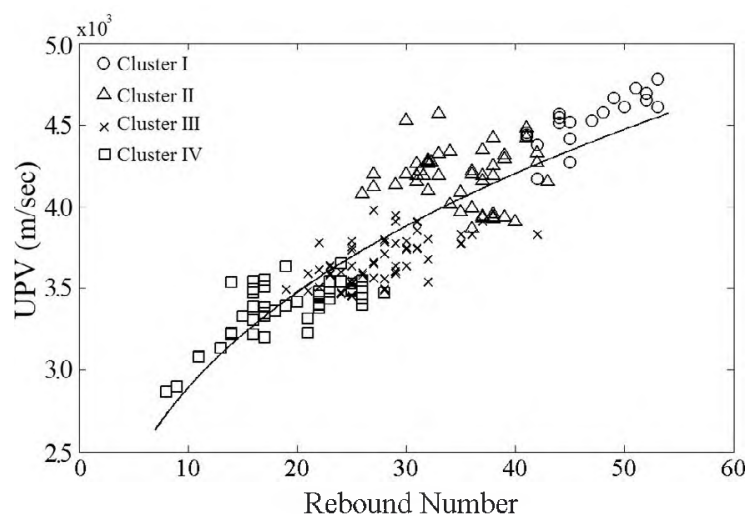

Fig. 7. Concrete quality classification results and relationship between UPV and RN.

results obtained in this study support combined usage of NDT results, a combined NDT-based concrete classification scheme using both the in-house and independent data was proposed. The authors chose to use all of the data to develop more comprehensive results. The optimal number of clusters were found to be four using a variant of $\mathrm{k}$-means clustering. Table 2 shows the centroid of these four clusters in the three-dimensional space of $U P V, R N$, and $f_{c}^{\prime}$. The data in each cluster are visually shown in Fig. 7, where each cluster is signified with a different symbol. The trend line between UPV and $\mathrm{RN}$ is also depicted in this figure. The trend line also confirms the direct relationship between these two tests. It can be seen in the figure that there are some intersections between the clusters indicating that specimens with same UPV/RN values may have different strength specifications. In other words, neither UPV nor RN by itself can provide accurate prediction of the compressive strength of concrete. Overall, the result of this concrete classification is expected to be useful for the field engineers and researchers for a rough estimation on concrete strength and quality. 


\section{Conclusions}

This paper used solely results on UPV and RH for prediction and classification of concrete strength, without a need for information about the concrete history and mixture proportions. The intent was to align models for in-situ predictions of existing structures. A rigorous statistical analysis with threefold cross-validation and application to independent data showed that combined usage of UPV and RN appeared to outperform models based on a single test result. This may be because UPV and RN are sensitive to the different characteristic of concrete. Based on this observation, a model is put forward for predictions of concrete strength. The proposed model was tested on independent data, and showed a very good predictive accuracy. Moreover, a table was proposed for concrete quality classification based on combined UPV and RN results. This table may be useful for researchers and engineers in the field for a rough estimation of in-situ concrete strength.

\section{Acknowledgment}

The authors thank Mr. Andrew Lesak for assistance with conducting experiments.

\section{References}

[1] A.M.T. Hassan, S.W. Jones, Non-destructive testing of Ultra High Performance Fibre Reinforced Concrete (UHPFRC): a feasibility study for using ultrasonic and resonant frequency testing techniques, Constr. Build. Mater. 35 (2012) 361-367.

[2] B. Abdul Hussein Ali, Assessment of Concrete Compressive Strength by Ultrasonic Non-Destructive Test. 2008.

[3] ACI Committee 228. Report on Nondestructive Test Methods for Evaluation of Concrete in Structures. Am Concr Inst, 2013, pp. 82.

[4] L. Rojas-henao, J. Fernández-gómez, J.C. López-agüí, Rebound hammer, pulse velocity, and core tests in self-consolidating concrete, ACI Mater. J. 109 (2012) 235-243.

[5] K. Szilágyi, A. Borosnyói, I. Zsigovics, Rebound surface hardness of concrete: introduction of an empirical constitutive model, Constr. Build. Mater. 25 (2011) 2480-2487.

[6] ACl Committee 228. In-Place Methods to Estimate Concrete Strength Reported. Am Concr Inst, 2003, pp. 44.

[7] H.Y. Qasrawi, Concrete strength by combined nondestructive methods simply and reliably predicted, Cem. Concr. Res. 30 (2000) 739-746.

[8] N. Delatte, D. Fowler, B. McCullough, High early strength bonded concrete overlay designs and construction methods for rehabilitation of CRCP. Res Rep 2911-4, 1996.

[9] H. Mesbah, M. Lachemi, P. Aitcin, Determination of elastic properties of highperformance concrete at early ages, $\mathrm{ACl}$ Mater. J. 99 (2002) 37-41.

[10] G. Washer, P. Fuchs, Ultrasonic testing of reactive powder concrete, IEEE Trans. Ultrason. Ferroelectr. Freq. Control 51 (2004) 193-201.

[11] ]. Popovics, Ultrasonic testing of concrete structures, Mater. Eval. 63 (2005) 50-55.

[12] H. Yoldirim, O. Sengul, Modulus of elasticity of substandard and normal concretes, Constr. Build. Mater. 25 (2011) 1645-1652.

[13] V. Malhotra, N. Carino, Handbook on Nondestructive Testing of Concrete, 2 nd ed., CRC Press, 2004.

[14] BS 1881-203. Testing Concrete. Recommendations for Measurement of Velocity of Ultrasonic Pulses in Concrete. Br Stand Institute, UK 1986.

[15] J. Bungey, M. Grantham, S. Millard, Testing of Concrete In Structures, third ed., Taylor \& Francis, 2006.

[16] D. Breysse, Nondestructive evaluation of concrete strength: an historical review and a new perspective by combining NDT methods, Constr. Build. Mater. 33 (2012) 139-163.

[17] C.H. Carvalho, J.B. Severo Junior, M.C.S.S. Macedo, S. Griza, Andrade, C.E.C. De. A.A. Dos Santos, et al., Application of statistical techniques to evaluate the reliability of ultrasonic and rebound hammer measurements of compressive strength in the concrete of bridges, Sci. Res. Essays 9 (2014) 136-144.

[18] J. Hoła, K. Schabowicz, New technique of nondestructive assessment of concrete strength using artificial intelligence, NDT E Int. 38 (2005) 251-259.

[19] Q. Huang, P. Gardoni, S. Hurlebaus, Predicting concrete compressive strength using ultrasonic pulse velocity and Rebound number, ACl Mater. J. 108 (2012) $403-412$.

[20] A. Samarin, P. Meynink, Use of combined ultrasonic and Rebound Hammer method for determining strength of concrete structural members, Concr. Int. 3 (1981) 25-29.

[21] S. Hannachi, M.N. Guetteche, Application of the combined method for evaluating the compressive strength of concrete on site, Open J. Civ. Eng. 2 (2012) 16-21.

[22] R. Ravindrajah, Y. Loo, C. Tam, Strength evaluation of recycled-aggregate concrete by in-situ tests, Mater. Struct. 21 (1988) 289-295.

[23] G. Kheder, A two stage procedure for assessment of in-situ concrete strength using combined non-destructive testing, Mater. Struct. 32 (1999) 410-417.

[24] RILEM. Draft recommendation for in-situ concrete strength determination by combined non-destructive methods. Mater. Struct., vol. 26, 1993, pp. 43-49.

[25] R. Miretti, M. Carrasco, R. Grether, C. Passerino, Combined non-destructive methods applied to normal-weight and lightweight-concrete, Insight 46 (2004) $748-753$

[26] B.S. Mohammed, N.]. Azmi, M. Abdullahi, Evaluation of rubbercrete based on ultrasonic pulse velocity and rebound hammer tests, Constr. Build. Mater. 25 (2011) 1388-1397.

[27] B. Hobbs, M.T. Kebir, Non-destructive testing techniques for the forensic engineering investigation of reinforced concrete buildings, Forensic Sci. Int. 167 (2007) 167-172.

[28] E. Arioglu, O. Manzak, Application of "Sonreb" Method to Concrete Sample Produced in Yedpa Construction Site. Prefabrication Union. Prefabr Union (in Turkish), 1991, pp. 5-12.

[29] R. Pucinotti, Reinforced concrete structure: non destructive in situ strength assessment of concrete, Constr. Build. Mater. (2015).

[30] ASTM C 597. Pulse Velocity Through Concrete. Annu B ASTM Stand ASTM Philadelphia (PA) 1989.

[31] ASTM C805. Standard Test Method for Rebound Number of Hardened Concrete. Annu B ASTM Stand ASTM Philadelphia (PA) 2013.

[32] ASTM C109. Standard Test Method for Compressive Strength of Hydraulic Cement Mortars. Annu B ASTM Stand ASTM Philadelphia (PA) 2013.

[33] P. Knaze, P. Beno. The use of combined non-destructive testing methods to determine the compressive strength of concrete, Mater. Struct. 17 (1984) 207 210.

[34] R. Domingo, S. Hirose, Correlation between concrete strength and combined nondestructive tests for concrete using high-early strength cement, Sixth Reg. Symp. Infrastruct. Dev. (8) (2009) 12-13.

[35] T. Lal, S. Sharma, S. Naval, Reliability of non-destructive tests for hardened concrete strength, Int. J. Eng. Res. Technol. 2 (2013) 1-7.

[36] A. Jain, A. Kathuria, A. Kumar, Y. Verma, K. Murari, Combined use of nondestructive tests for assessment of strength of concrete in structure, Procedia Eng. 54 (2013) $241-251$

[37] N. Nguyen, Z. Sbartaï, ]. Lataste, Assessing the spatial variability of concrete structures using NDT techniques-laboratory tests and case study, Constr. Build. Mater. Build. Mater. 49 (2013) 240-250.

[38] N.R. Draper, H. Smith, Applied Regression Analysis, Wiley, 1981.

[39] J. Hjorth, Computer Intensive Statistical Methods: Validation, And Bootstrap. John Wiley \& Sons, Model Selection, 1993.

[40] RILEM TC. NDT 1 Testing of Concrete by the Ultrasonic Pulse Method. E \& FN SPON; 1972.

[41] M. Erdal, Prediction of the compressive strength of vacuum processed concretes using artificial neural network and regression techniques, Sci. Res. Essay (4) (2009) 1057-1065.

[42] W. Krzanowski, Principles of Multivariate Analysis, Clarendon, 2000.

[43] D. Arthur, S. Vassilvitskii, k-Means++: The Advantages of Careful Seeding. Proc Eighteenth Annu ACM-SIAM Symp Discret Algorithms, 2007, pp. 1027-1035.

[44] S. Lloyd, Least squares quantization in PCM, Inf. Theory, IEEE Trans. 28 (1982) $129-137$.

[45] M.K. Lim, H. Cao, Combining multiple NDT methods to improve testing effectiveness, Constr. Build. Mater. 38 (2013) 1310-1315.

[46] J. Les]ie, W. Cheesman, An ultrasonic method of studying deterioration and cracking in concrete structures, J. Am. Concr. Inst. 46 (1949) 17-36. 